\title{
Estruturas secretoras em Cipó-d'alho (Mansoa standleyi (Steyerm.) A. H. Gentry, Bignoniaceae): ocorrência e morfologia
}

\author{
Raimunda Conceição VILHENA-POTIGUARA ${ }^{1}$, Ana Cristina Andrade de AGUIAR-DIAS², Tatiani Yuriko \\ Souza KIKUCHI ${ }^{3}$, Ana Carla Feio dos SANTOS $^{4}$, Rolf Junior Ferreira SILVA ${ }^{5}$
}

\begin{abstract}
RESUMO
Espécies de Mansoa são denominadas de "cipó-d'alho", por exalarem odor de alho das partes vegetativas e reprodutivas. Contudo, dados sobre morfologia e distribuição das estruturas secretoras presentes em Mansoa sáo escassos e ausentes para $M$. standleyi. O presente trabalho objetivou caracterizar a ocorrência e morfologia das estruturas secretoras do eixo vegetativo aéreo de M. standleyi. Para tanto, amostras da lâmina foliolar e de regióes nodais foram fixadas e submetidas às técnicas histológicas e de microscopia eletrônica de varredura. Testes histoquímicos, com os respectivos controles foram aplicados nas estruturas secretoras em fase secretora. Indivíduos de formigas e moscas, que visitavam a espécie foram amostrados, preservados e identificados por entomólogo. As estruturas secretoras do eixo vegetativo aéreo de $M$. standleyi estáo representadas por tricomas glandulares dos tipos pateliformes e peltados. Todos com desenvolvimento assincrônico e presentes nas regióes nodais e lâmina foliolar, principalmente nas partes mais jovens. Nas regióes nodais, os tricomas formam um complexo secretor e, na lâmina foliolar, estâo dispersos. As análises histoquímicas revelaram que os tricomas pateliformes são de fato nectários extraflorais e que os tricomas peltados, apresentam uma fração de alcaloides. Os visitantes das glândulas nodais correspondem a formigas Crematogaster (Formicidae) e Ectatomma brunea (Vespoidea, Formicidae) e moscas Oxysarcodexia (Sarcophagidae, subfamília Utitidae (Ulidiidae). Mansoa standleyi possui as estruturas secretoras do eixo vegetativo aéreo semelhantes às citadas pela literatura para Bignoniaceae, sendo esta a primeira vez, que um nectário extrafloral é descrito para a espécie.
\end{abstract}

PALAVRAS-CHAVE: Tricomas glandulares, nectários extraflorais, interação inseto-planta.

\section{Secretory structures in Cipó-d'alho (Mansoa standleyi (Steyerm.) A. H. Gentry, Bignoniaceae): occurrence and morphology}

\begin{abstract}
Species of Mansoa are called "cipó-d'alho" because of the smell of garlic that wafts from their vegetative and reproductive parts. Since data on the morphology and occurrence of their secretory structures are scarce and even absent for $M$. standleyi, the present work characterizes the distribution and morphology of such structures in the vegetative aerial axis of the latter. To do so, samples of the leaf blade and of nodal regions were fixed and examined using histological and scanning electron microscope techniques. Histochemical tests with appropriate controls were carried out on the secretory structures during the secretory phase. Fly and ant individuals that visit the species were sampled, preserved and identified by an entomologist. The secretory structures of the vegetative aerial axis of $M$. standleyi are peltate and patelliform glandular trichomes. All develop asynchronously and are present in the nodal regions and leaf blade, mainly in their youngest parts. Trichomes form a secretory complex in the nodal regions while they are scattered in the leaf blade. Histochemical analyses revealed that the cupulate and patelliform trichomes are extrafloral nectaries and that the peltate ones present an alkaloid fraction. The visitors of the nodal glands are ants Crematogaster (Formicidae) and Ectatomma brunea (Vespoidea, Formicidae) and flies Oxysarcodexia (Sarcophagidae, subfamily Utitidae [Ulidiidae]). The secretory structures of the vegetative aerial axis of Mansoa standleyi are similar to those reported for Bignoniaceae. An extrafloral nectary is described for $M$. standleyi for the first time.
\end{abstract}

KEYWORDS: Glandular trichomes, extrafloral nectaries, insect-plant interaction, Bignoniaceae.

\footnotetext{
1 Museu Paraense Emílio Goeldi, Coordenação de Botânica, Av. Magalhães Barata, 376, 66040-170, São Braz, Belém, PA, Brasil, Caixa Postal 399.

2 Universidade Federal do Pará, Instituto de Ciências Biológicas, CEP: 66075-110, Belém, PA, Brasil. acaaguiar@yahoo.com.br

${ }^{3}$ Museu Paraense Emílio Goeldi, Coordenação de Botânica, Av. Magalhães Barata, 376, 66040-170, São Braz, Belém, PA, Brasil, Caixa Postal 399. typinheiro@yahoo.com.br

${ }^{4}$ Museu Paraense Emílio Goeldi, Coordenação de Botânica, Av. Magalhães Barata, 376, 66040-170, São Braz, Belém, PA, Brasil, Caixa Postal 399. carlinhafeio@gmail.com

${ }^{5}$ Instituto Nacional de Pesquisas da Amazônia, Coordenação de Botânica, Av. André Araujo, 2936, 69060-001, Aleixo, Manaus, AM, Brasil. rolfjr@hotmail.com
} 


\section{INTRODUÇÃO}

Bignoniaceae Juss. é representada por cerca de 82 gêneros e 875 espécies, que estão distribuídas predominantemente nos neotrópicos, onde a maioria são lianas (Lohmann e Ulloa 2007; Olmstead et al. 2009), tendo o Brasil como principal centro de diversidade (Gentry 1980; 1990).

Com base no hábito e na deiscência dos frutos, a família foi segregada em oito tribos (Gentry 1980), contudo, estudos morfológicos e moleculares reconhecem apenas sete, sendo estas: Bignonieae, Coleeae, Crescentieae, Eccremocarpeae, Oroxyleae, Tecomeae e Tourrettieae (Spangler e Olmstead 1999; Olmstead et al. 2009).

No Brasil ocorrem quatro tribos, compreendendo cerca de 51 gêneros e 450 espécies (Gentry 1973). O grupo é constituído por plantas lenhosas, com folhas opostas e compostas, flores hermafroditas, zigomorfas, gamopétalas, oligostêmones, estames didínamos, epipétalos, com estaminódios presentes, gineceu sincárpico, ovário súpero, estilete bífido e fruto do tipo cápsula (Souza e Lorenzi 2008; Judd et al. 2009). Algumas espécies são utilizadas como ornamentais e madeireiras, possuindo, também, potencial aromático e medicinal (Berg 1993).

Dentre as principais características para a adaptação e o sucesso reprodutivo destacam-se as defesas antiherbivoria, exemplificadas pelas estruturas secretoras (nectários e tricomas glandulares), peculiares às espécies de Bignoniaceae (Lohmann 2008), que foram relatadas tanto para órgãos vegetativos (Martins et al. 2008), quanto reprodutivos (Rivera 2000a; Rivera 2000b). Para Metcalfe e Chalk (1979) e Rivera (2000a), as diferenças anatômicas de distribuição e desenvolvimento das estruturas secretoras podem constituir caracteres de importância taxonômica. A análise química do óleo essencial das folhas de Mansoa standleyi (Steyerm.) A.H. Gentry indicou que os compostos ativos são substâncias triterpênicas, flavonoides, naftoquinonas, aminoácidos e sulfetos (Trindade et al. 2008), entretanto, ainda é desconhecido o sítio de liberação e/ou armazenamento destes exsudatos.

$\mathrm{Na}$ Amazônia brasileira, espécies de Mansoa DC. são conhecidas como "cipó-d'alho" devido ao forte odor de alho exalado do caule, folhas, flores e frutos. A semelhança morfológica entre as espécies deste gênero provoca confusão na identificação e até mesmo falsificação na comercialização do produto medicinal (Jorge Oliveira com. pess.).

Mansoa standleyi possui atributos semelhantes aos do alho (Allium sativum L.), como o aroma e o sabor, além de substâncias químicas que apresentam propriedades anticancerígena, antilipídica, antihistamínica e antitrombótica (Moraes 2008). No nordeste paraense a espécie é cultivada em quintais de populaçôes tradicionais, onde é utilizada como condimento e para fins medicinais.
As estruturas secretoras em espécies de Mansoa são objetos de estudos diversos, abordando aspectos estruturais (Elias e Gelband 1976; Galetto 1995; Andrade 2008) e ecológicos (Subramanian e Inamdar 1989, Thomas e Dave 1992; Belmonte et al. 1994), porém, são escassas as informaçóes sobre anatomia (Andrade 2008), taxonomia (Seibert 1948), ontogenia, ultraestrutura, processo de secreção e química (Zoghbi et al. 2007). Outrossim, considerando que as propriedades químicas estáo relacionadas com as estruturas secretoras presentes nos caules e nas folhas, um estudo criterioso faz-se necessário, principalmente para M. standleyi que não apresenta registros na literatura quanto a estes dados. A abordagem da natureza química do material secretado, juntamente com a morfologia, contribui para a compreensão do exato papel destas estruturas, bem como a função do produto secretado pela planta.

O objetivo do presente trabalho foi caracterizar a morfologia e distribuição das estruturas secretoras do eixo vegetativo aéreo de Mansoa standleyi, visando diminuir a lacuna existente no grupo, além de levantar caracteres que auxiliem na correta identificação do táxon.

\section{MATERIAL E MÉTODOS}

O material botânico foi coletado de indivíduos de Mansoa standleyi, no Campus de Pesquisa do Museu Paraense Emílio Goeldi (MPEG), Coordenação de Botânica, Belém, PA $\left(1^{\circ} 27^{\prime} 5,69^{\prime \prime}\right.$ e e $\left.48^{\circ} 26^{\prime} 40,38^{\prime} \mathrm{O}\right)$ com exsicata depositada no acervo do herbário MG, sob o registro MG 188.715.

Para verificar a ocorrência de glicose na secreção, utilizouse glicofita Plus, no habitat natural da espécie. Três indivíduos foram testados do primeiro ao quinto nó visível.

Para verificar os possíveis visitantes foram marcados cinco ramos jovens, observados ao longo de quatro dias seguidos durante o período de luminosidade (8:00-18:00h), nos meses de maio, junho e julho de 2010. As formigas e moscas observadas visitando as glândulas e coletando o exsudato foram preservadas em etanol $70 \%$ para posterior identificaçáo.

Para o estudo anatômico das estruturas secretoras, amostras foram retiradas de lâminas foliolares nos estágios jovem (4,5 $\mathrm{cm}$ de comprimento x 1,2 cm de largura) e adulto $(19,3 \mathrm{~cm}$ de comprimento $8 \mathrm{~cm}$ largura), bem como da regiáo nodal ( $1^{\circ}, 3^{\circ}$ e $5^{\circ}$ nós visíveis), fixadas em $\mathrm{FAA}_{70}$ (Formaldeído + Ácido acético + Álcool etílico 70\%), por 24 horas e em FNT (Formalina Neutra Tamponada) (Lillie 1965), por 48 horas, mantidas em vácuo e, posteriormente, desidratadas em série butílica (Johansen 1940) e incluídas em Paraplast ${ }^{\circ}$. Secçôes seriadas transversais e longitudinais foram feitas em micrótomo rotativo de avanço automático (modelo Leica ${ }^{\circ}$ RM 2245), com $12-15 \mu \mathrm{m}$ de espessura, coradas com safranina 
e azul de astra (Gerlach 1969) e montadas entre lâmina e lamínula em resina sintética Permount ${ }^{\oplus}$.

Para a análise da superfície das estruturas secretoras,

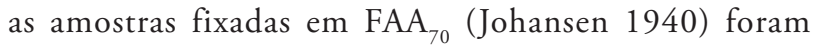
desidratadas em série etílica crescente, secas pelo método de ponto crítico de $\mathrm{CO}_{2}$, montadas em suportes metálicos e metalizadas com ouro em camada de $20 \mathrm{~nm}$ de espessura, por 150 segundos em corrente de $25 \mathrm{~mA}$.

Testes histoquímicos foram aplicados nas estruturas secretoras para a localização in situ das principais classes de compostos químicos que constituem a secreção: reação de PAS para carboidratos (McManus 1948), vermelho de rutênio para mucilagens ácidas (Johansen 1940), preto de Sudão B para lipídios totais (Pearse 1985), cloreto férrico para compostos fenólicos totais (Johansen 1940) e reagente de Dragendorff para alcaloides (Yoder e Mahlberg 1976), sendo realizado controle em todos os testes. Algumas secçōes também foram montadas e observadas sem tratamento para a verificaçáo do aspecto natural da secreção (branco).

As fotomicrografias foram realizadas com auxílio de câmera fotográfica digital Canon PowerShot A660IS, acoplada ao microscópio Zeiss Axiostar plus. As eletromicrografias de varredura, foram obtidas por captura em microscópio Leo (modelo $1450 \mathrm{VP}$ ), que opera com Software Leo, utilizando-se detectores de elétrons secundários (ES) e aceleração eletrônica de $12.50 \mathrm{kV}$, e as demais ilustraçóes obtidas em câmera digital Sony Cyber-Shot 6.0. As mensuraçóes das glândulas foram efetuadas em 12 estruturas em fase de liberação do conteúdo pela escala de medida da eletromicrografia de varredura.

\section{RESULTADOS E DISCUSSÃO}

Mansoa standleyi possui dois tipos de tricomas glandulares no eixo vegetativo aéreo - tricomas do tipo pateliforme (Figura 1A) e peltado (Figura 1B). Estes se distribuem em maior quantidade nas regióes mais jovens (Figura 1C). Na região nodal é possível observar um complexo de glândulas que ocupam a regiáo interpeciolar dos primeiros nós visíveis (Figuras 1D, 1F).

Estes tricomas apresentam desenvolvimento assincrônico e estão localizados na região interpeciolar (Figuras 2A-2B) e na lâmina foliolar (Figura $2 \mathrm{C}$ ), possuindo origem protodérmica (Figura 2B).
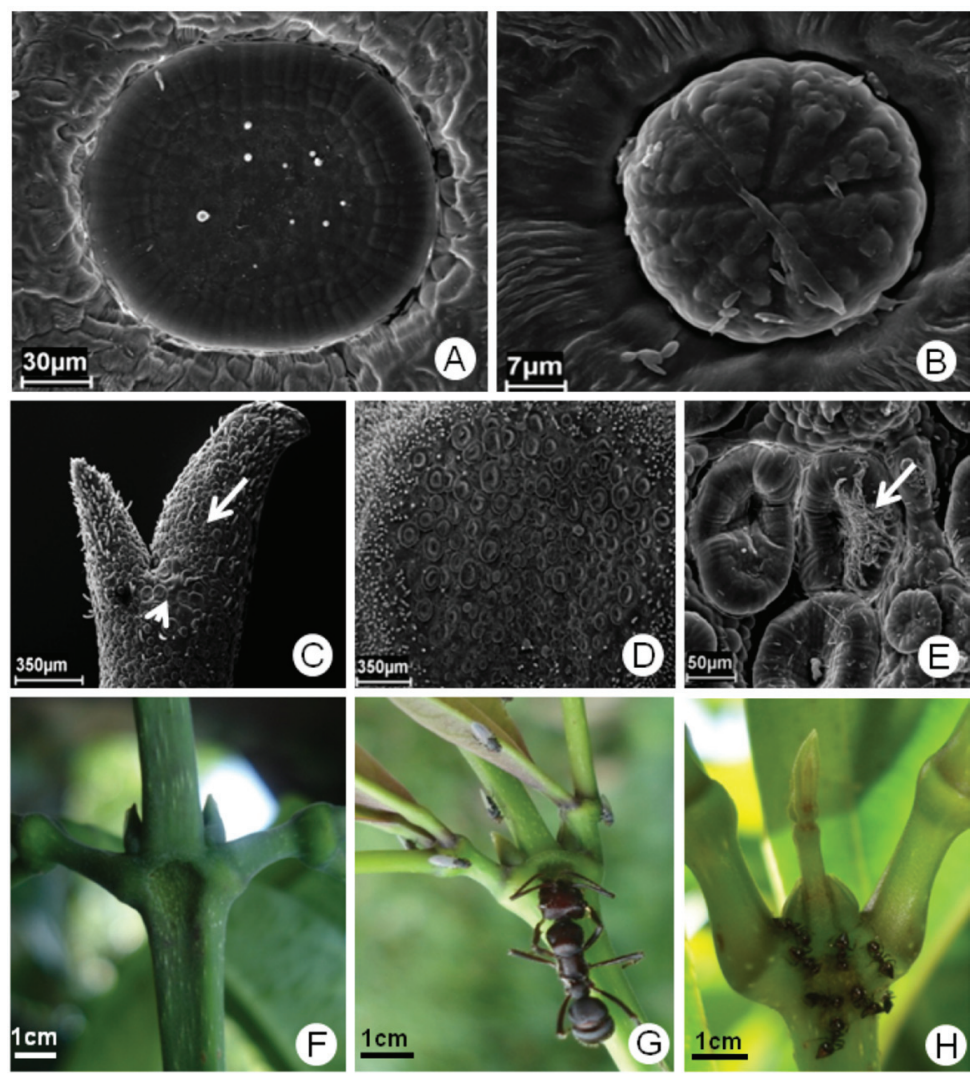

Figura 1 - Eletromicrografias de varredura do eixo caulinar de Mansoa standleyi. A. Tricoma pateliforme. B. Tricoma peltado. C. Ápice caulinar, notar a formação do complexo glandular com tricomas pateliformes na região axilar (ponta de seta) e ao redor tricomas peltados (seta). D. Detalhe do complexo glandular dos tricomas pateliformes. E. Tricomas pateliformes com hifas fúngicas (seta). F-H: Indivíduos de Mansoa standleyi cultivados no MPEG. F. Detalhe da região nodal. G-H. Região nodal visitada por insetos. 


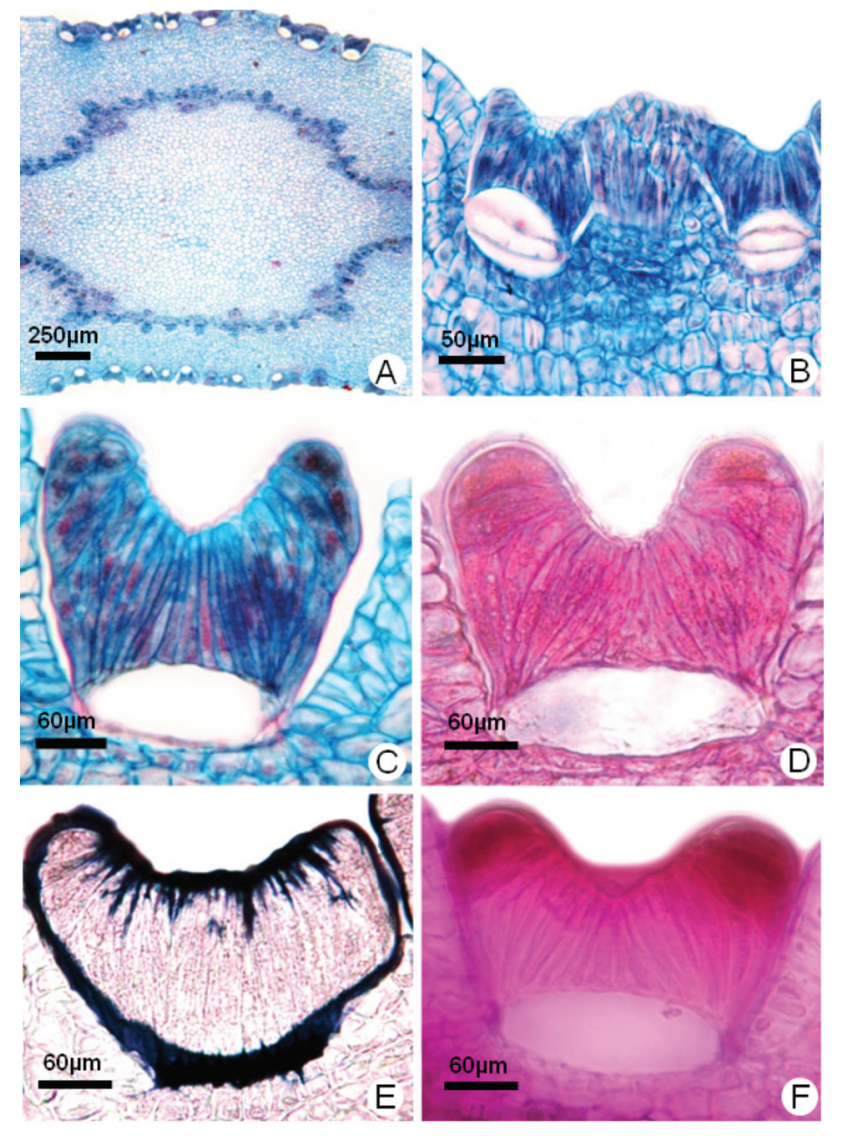

Figura 2 -Tricomas pateliformes em Mansoa standleyi. A. Vista geral da região nodal com tricomas em ambas as faces. B. Estruturas com desenvolvimento assincrônico. C. Fase secretora, notar conteúdo denso. D. Resultado positivo para mucilagem com vermelho de rutênio. E. Cutícula evidenciada pelo preto de Sudão B. F. Detecção de carboidratos com PAS.

Andrade (2008), ao inventariar o eixo vegetativo da mesma espécie, registrou a presença do tricoma glandular do tipo peltado apenas para a lâmina foliolar. Náo sendo registrada a ocorrência do tipo pateliforme, tanto para a lâmina, quanto para a região interpeciolar. $\mathrm{O}$ registro deste tipo de tricoma confere um dado inédito para a espécie.

Indivíduos de formigas - Crematogaster e Ectatomma brunea (Vespoidea) pertencentes à família Formicidae e subfamília Formicinae - e moscas - Oxysarcodexia (Sarcophagidae) da subfamília Utitidae (Ulidiidae) - foram observados visitando as glândulas em dois períodos ao longo do dia (8:00-10:00 h e das 15:00-18:00 h) (Figuras 1G-1H). Estes indivíduos visitaram todos os seis primeiros nós da planta, não permitindo o acesso de outros animais. A interação inseto-planta é facilmente observada entre os insetos registrados nos indivíduos de $M$. standleyi analisados, que coletam o exsudato. A presença de estruturas secretoras que liberam exsudatos como recompensa aos insetos, como nectários e compostos lipídicos possibilita a relação mutualística entre plantas e determinados insetos, especialmente formigas. Estas desempenham uma importante função na proteção contra a herbivoria (Bentley 1977; Keeler 1980; Elias 1983).

$\mathrm{Na}$ regiāo interpeciolar, os tricomas pateliformes formam um complexo secretor (Figura 2A). Na regiáo apical destes tricomas forma-se uma concavidade sem orifício (Figuras 2B-2F). Hifas de fungo podem ser encontradas por toda superfície epidérmica (Figura 1E). Já na lâmina foliolar, os tricomas patelifomes estão presentes, porém não apresentam a mesma organização, ocorrendo de forma isolada e dispersa em ambas as faces.

$\mathrm{Na}$ regiâo apical destes tricomas, observa-se as células em paliçada; as paredes periclinais e anticlinais das células epidérmicas são recobertas por cutícula (Figura 2E, 3F). Nas regióes laterais, a cutícula é observada apenas na parede periclinal externa das células epidérmicas (Figura 2C).

A epiderme secretora é uniestratificada, apresentando formato colunar com paredes delgadas e núcleo proeminente, com altura variando de 30-50 $\mu \mathrm{m}$ (Figura 2B). Abaixo da cabeça secretora é observada uma única célula basal formando o pedúnculo com protoplasto e núcleo evidente (Figura 2C). Abaixo deste tipo de tricoma é verificado um grupo de células subepidérmicas reduzidas (Figura 2B). Acreditase que as células secretoras liberam seu exsudato na região subcuticular, atravessando a parede e a cutícula, sem sua ruptura para em seguida ocorrer à liberaçáo do exsudato para o meio extracelular.

Elias e Prance (1978) utilizaram o formato dos nectários para separar espécies de gêneros distintos dentro da Tribo Bignonieae, tais como: Adenocalymma Mart. ex Meisn., Amphilophium Kunth, Amphitecna Miers, Anemopaegma Mart. ex Meisn., Arrabidaea DC., Crescentia L., Distictella Kuntze, Haplophragma Dop, Incarvillea Juss., Jacaranda Juss, Melloa Bureau, Memora Miers, Pachyptera DC. ex Meisn., Pithecoctenium Mart. ex Meisn., Spathodea P. Beauv., Tabebuia Gomes ex DC. e Tanaecium Sw. Em que foi descrito o tricoma pateliforme como o tipo que possuía apenas uma célula basal e o cupuliforme como o tipo que possuía mais de uma célula basal de formato cúbico. No entanto, Rivera (2000a), ao estudar o cálice de espécies argentinas de Bignoniaceae, constatou que o mesmo indivíduo pode apresentar os dois formatos, propondo que este caráter fosse utilizado apenas para caracterizar morfologicamente as glândulas. Como em $M$. standleyi foi constatada apenas a presença do tipo pateliforme, não foi possível verificar o valor taxonômico que tais caracteres para nível específico.

Os tricomas glandulares de $M$. standleyi seguem o mesmo padrão daqueles descritos no eixo reprodutivo de Arrabidaea coralina (Jacq.) Sandwith, Arrabidaea selloi (Spreng.) Sandwith, Dolichandra cynanchoides Cham., Macfadyena unguis-cati (L.) A.H. Gentry e Tecoma stans (L.) Juss. ex Kunth (Rivera 2000a). 

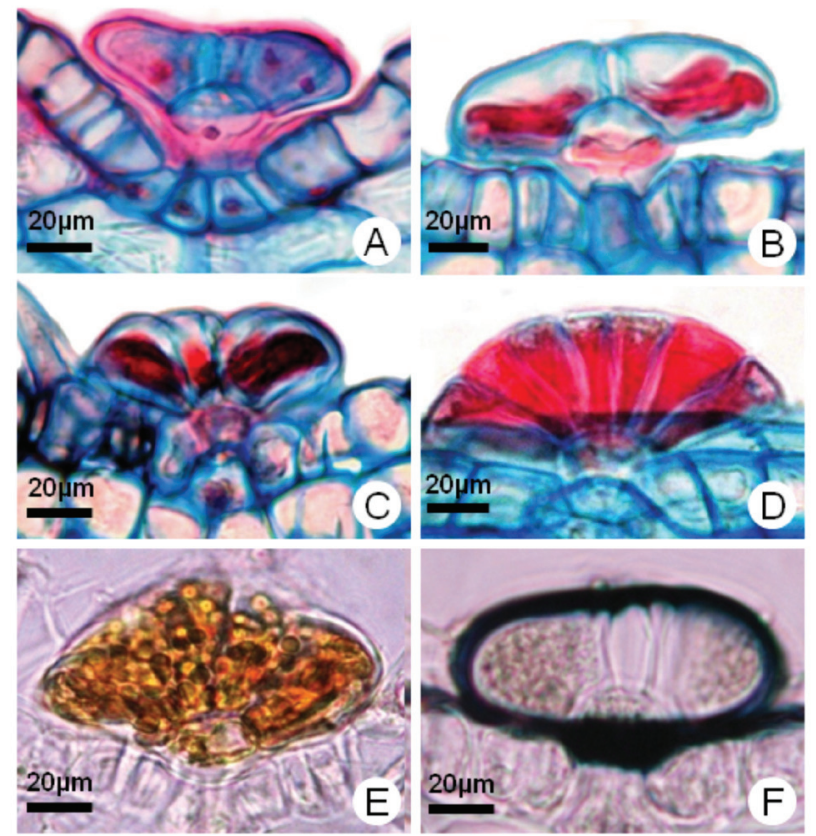

Figura 3 - Tricomas peltados em Mansoa standleyi. A. Tricoma em fase présecretora. B-C. Tricoma em fase secretora. D. Tricoma em fase pós-secretora. E. Alcaloides detectados com reagente de Dragendorff. F. Cutícula evidenciada pelo preto de Sudão B.

Entretanto, difere de T. stans que apresenta uma série de células cuboides na base. Ao contrário dos tricomas pateliformes, os tricomas peltados observados em $M$. standleyi distribuem-se ao longo dos seis primeiros nós visíveis e ocorrem em grande quantidade nos primeiros nós, decrescendo à medida que o eixo vegetativo aéreo se desenvolve e ocorre a instalação do crescimento secundário, havendo a substituição da epiderme pela periderme. Nos folíolos, distribuem-se de forma mais espaçada, semelhante aos tricomas pateliformes. Possuem desenvolvimento assincrônico, tanto no caule quanto nos folíolos, podendo estar invaginados (Figura 3A) ou no mesmo nível das células epidérmicas (Figura 3B). A porção secretora é multicelular, cujo número de células varia de oito a 16 , e o pedúnculo é unicelular (Figuras 3A-3D).

Acredita-se que exista uma relação entre os tricomas patelifomes e os tricomas peltados em Bignoniaceae. Alguns autores sugerem que os pateliformes originaram-se dos peltados (Elias e Newcombe 1979). Tal semelhança é verificada em $M$. standleyi, porém, para corroborar a relaçáo filogenética entre estas estruturas faz-se necessário a realização de mais estudos anatômicos que abordem um número maior de espécies da família.

As estruturas secretoras observadas em $M$. standleyi por se tratarem de tricomas glandulares não são vascularizadas e os feixes mais próximos a estas estruturas pertencem ao cilindro vascular caulinar (Figura 2A). Na maioria das espécies de
Bignoniaceae que possuem estruturas secretoras semelhantes às descritas para $M$. standleyi, as glândulas são caracterizadas como não vascularizadas (Elias 1983). No entanto, Tecoma stans é descrita como sendo vascularizada por Subramanian e Inamdar (1989).

A análise histoquímica dos exsudatos das estruturas secretoras descritas revelou que as mesmas exsudam compostos distintos (Tabela 1). Nos tricomas glandulares pateliformes foi observada uma secreção heterogênea com a presença de mucilagens ácidas e carboidratos (Figura 2D), não havendo o registro de substâncias lipofílicas (Figuras 2E, 3F). A presença de glicose na secreção destes tricomas foi evidenciada pelo uso da glicofita. Com a constatação da presença deste composto na secreção destes tricomas e o registro de formigas coletando este néctar, tais estruturas foram identificadas como nectários extranupciais (Figura 2F).

A existência de nectários em Bignoniaceae é um caráter relevante para a taxonomia do grupo. Em Tecomaria campensis Thunb tais estruturas foram registradas apresentando uma importante defesa contra a herbivoria, com a ocorrência de nectários vascularizados e não vascularizados (Subramanian e Inamdar 1989).

Já nos tricomas peltados, apenas uma fração de alcaloides foi detectada (Figura 3E). A presença de compostos bioativos, como os alcaloides, está relacionada à estratégias de defesa, envolvidos nas respostas contra herbívoros e patógenos (Brown 1981). O fato da planta exalar o odor de alho pode está relacionado com a presença deste composto bioativo, já que o alcaloide em contato com o ar pode exalar odores fortes que auxiliam na proteção contra a herbivoria (DeLuca e Cutler 1987). Em ambas as estruturas, a secreção foi registrada apenas no meio intracelular (Figuras 2D-3E).

A existência de tricomas glandulares é uma estratégia de defesa que a planta desenvolve à medida que a seleçáo natural

Tabela 1 - Resultado dos testes histoquímicos aplicados nas estruturas secretoras do eixo vegetativo aéreo de Mansoa standleyi.

\begin{tabular}{cccc}
\hline Testes & $\begin{array}{c}\text { Metabólitos } \\
\text { evidenciados }\end{array}$ & $\begin{array}{c}\text { Tricomas } \\
\text { pateliformes }\end{array}$ & $\begin{array}{c}\text { Tricomas } \\
\text { peltados }\end{array}$ \\
\hline vermelho de rutênio & mucilagens ácidas & + & - \\
preto de Sudão B & lipídios totais & - & - \\
Dragendorff & alcaloides & - & + \\
cloreto férrico & $\begin{array}{c}\text { compostos } \\
\text { fenólicos }\end{array}$ & - & - \\
PAS & carboidratos & + & + \\
\hline
\end{tabular}

Notas: ( + ) reação positiva; ( - ) reação negativa 
favorece a diminuiçáo de danos no vegetal, em especial nas folhas. Mais especificamente, a seleção age diretamente sobre as características de defesa, proporcionando vantagens ao vegetal. Tricomas são constituíntes da epiderme, distribuídos em diferentes partes da planta que ocupam regiôes estratégicas para defesa contra herbívoros. Na maioria dos trabalhos realizados para a família, os tricomas glandulares que apresentam o mesmo formato que os observados em $M$. standleyi são definidos como nectários, mesmo sem a realização de testes que elucidem esta questão. Diante das análises realizadas, foi possível concluir que os tricomas pateliformes são de fato, nectários extraflorais. A presença de NEFs possibilita a relação mutualística entre plantas e determinados insetos, especialmente formigas. Estas desempenham uma importante função na proteção contra a herbivoria, além de deterem outros organismos que reduzem a capacidade reprodutiva das plantas (Bentley 1977; Keeler 1980; Elias 1983).

\section{CONCLUSÕES}

Mansoa standleyi apresenta semelhança entre os tricomas glandulares observados no eixo vegetativo aéreo com os descritos na literatura para Bignoniaceae, evidenciando assim, a importância destes caracteres para o conhecimento e delimitação do grupo. Dentre os dois tipos de tricomas descritos, o tipo pateliforme é descrito anatomicamente pela primeira vez para a espécie, sendo caracterizado como nectário extrafloral.

\section{AGRADECIMENTOS}

Ao doutorando Fernando Carvalho Filho do Laboratório de Entomologia - Coordenação de Zoologia do MPEG, pela identificaçáo dos insetos e ao Laboratório de Aracnologia do MPEG, pelo empréstimo do microscópio para a captura das imagens estruturais.

\section{BIBLIOGRAFIA CITADA}

Andrade, C.R.S. 2008. Morfoanatomia dos órgãos vegetativos de Mansoa standleyi (Steyerm.) A. H. Gentry (Bignoniaceae). Dissertação de Mestrado. Universidade Federal Rural da Amazônia/Museu Paraense Emílio Goeldi, Pará, Belém. 100 pp.

Belmonte, E.; Cardemil, L.; Arroyo, M.T.K. 1994. Floral nectary structure and nectar composition in Eccremocarpus scaber (Bignoniaceae), a hummingbird-pollinated plant of Chile. American Journal of Botany, 81:493-503.

Bentley, B.L. 1977. The protective function of ants visiting the extrafloral nectaries of Bixa orellana L. (Bixaceae). Journal of Ecology, 65: 27-38.

Berg, M.E. 1993. Plantas medicinais na Amazônia: contribuição ao seu conhecimento sistemático. Museu Paraense Emílio Goeldi. Belém, PA. 268 pp.
Brown, K.S.Jr. 1981. The biology of Heliconius and related genera. Annual Review Entomology, 26: 427-456.

DeLuca, V.; Cutler, A.J. 1987. Subcellular localization of enzymes involved in indole alkaloid biosynthesis in Catharanthus roseus. Plant Physiology, 85: 1099-1102.

Elias, T.S.; Gelband, H. 1976. Morphology and anatomy of floral and extrafloral nectaries in Campsis (Bignoniaceae). American Journal of Botany, 63: 1349-1353.

Elias, T.S.; Prance, G.T. 1978. Nectaries on the fruit of Crescentia and other Bignoniaceae. Brittonia, 30: 175-181.

Elias T.S.; Newcombe, L.F. 1979. Foliar nectaries and glandular trichomes in Catalpa (Bignoniaceae). Acta Botanica Sinica, 21: 215-224.

Elias, T.S. 1983. Extrafloral nectaries: their structure and distribution. p. 174-203. In: Bentley, B. L.; Elias, T. S. (eds.). The biology of nectaries. Columbia University Press, New York.

Galetto, L. 1995. Nectary structure and nectar characteristics in some Bignoniaceae. Plant Systematics and Evolution, 196: 99-121.

Gentry, A.H. 1973. Generic delimitations of Central American Bignoniaceae. Brittonia, 25: 226-242.

Gentry, A.H. 1980. Bignoniaceae. Part I. Tribes Crescentieae and Tourrentieae. Flora Neotropica, 25(1): 1-130.

Gentry, A.H. 1990. Floristic similarities and differences between Southern Central America and upper and Central Amazonia. p.141-160. In: Four neotropical rain forests (A.H. Gentry, ed.). Yale University Press, London.

Gerlach, D. 1969. Botanische Mikrotechnik, Eine Einfuhrung. Georg Thieme Verlag, Stuttgart. 311 pp.

Johansen, D.A. 1940. Plant Microtechnique. Mcgraw-Hill, New York. 523 pp.

Judd, W.S.; Campbell, C.S.; Kellog, E.A.; Stevens, P.F.; Donoghue, M.J. 2009. Sistemática vegetal: um enfoque filogenético. $3^{\mathrm{a} e d .}$ Artmed, Porto Alegre. 486 pp.

Keeler, K.H. 1980. The extrafloral nectaries of Ipomoea leptophylla (Convolvulaceae). American Journal of Botany, 67: 216-222.

Lillie, R.D. 1965. Histopathologic technic and pratical histochemistry. $3^{\mathrm{a} e d .}$ McGraw Hill, New York.

Lohmann, L.G.; Ulloa, C.U. 2007. Bignoniaceae in iPlants prototype checklist [online]. (www.iplants.org). Acesso em 15/08/2010.

Lohmann, L.G. 2008. Adaptaçôes em Anemopaegma Mart. ex Meisn (Bignoniaceae): evolução de nectários extraflorais e tricomas como estruturas de defesa anti-herbivoria. (www.bv.fapesp.br/ projetos-regulares/6389/adaptacoes-anemopaegma-mart-exmeisn-bignoniaceae). Acesso em 15/08/2010.

Martins, M.B.G.; Castro, A.A.; Cavalheiro, A.J. 2008. Caracterização anatômica e química de folhas de Jacaranda puberula (Bignoniaceae) presente na Mata Atlântica. Revista Brasileira de Farmacognosia, 18: 600-607.

McManus, J.F.A. 1948. Histological and histochemical uses of periodic acid. Stain Technology, 23: 99-108. 
Metcalfe, C.R.; Chalk, L. 1979. Anatomy of the dicotyledons. Claredon Press, Oxford. 276 pp.

Moraes, M.L. 2008. Tradição e modernidade no uso de essências. Informativo do Museu Paraense Emílio Goeldi, Destaque Amazônia, 24: 1-8.

Olmstead, R.G.; Zjhra, M.L.; Lohmann, L.G.; Grose, S.O.; Eckert, A.J. 2009. A molecular phylogeny and classification of Bignoniaceae. American Journal of Botany, 96: 1731-1743.

Pearse, A.G.E. 1985. Histochemistry: theoretical and applies. Livingstone, C. Edinburgh. 1055 pp.

Rivera, G.L. 2000a. Nectarios extranupciales florales en especies de Bignoniaceae de Argentina. Darwiniana, 38: 1-10.

Rivera, G.L. 2000b. Nupcial nectary structure of Bignoniaceae from Argentina. Darwiniana, 38: 227-239.

Seibert, R.J. 1948. The use of glands in a taxonomic consideration of the family Bignoniaceae. Annals of the Missouri Botanical Garden, 35: 123-137.

Souza, V.C.; Lorenzi, H. 2008. Botânica sistemática: guia ilustrado para identificação das famílias de Fanerógamas nativas e exóticas no Brasil, baseado em APG, II. Instituto plantarum, Nova Odessa. 2. p. 574-581.

Spangler, R.J.; Olmstead, R.G. 1999. Phylogenetic analysis of Bignoniaceae based on the $c p$ DNA gene sequences $r b c L$ and ndhF. Annals of the Missouri Botanical Garden, 86: 33-46.

Subramanian, R.B.; Inamdar, J.A. 1989. The structure, secretion and biology of nectaries in Tecomaria capensis Thumb. (Bignoniaceae). Phytomorphology, 39: 69-74.
Thomas, V.; Dave, Y. 1992. Structure and biology of nectaries in Tabebuia serratifolia Nichols (Bignoniaceae). Botanical Journal of the Linnean Society, 109: 395-400.

Trindade, N.S.; Arruda, A.C.; Almeida, E.S.; Souza, J.R.V.; Lobato, M.P.; Souza, R.F.; Arruda, M.S.P. 2008. Triterpenos isolados das folhas de Mansoa standleyi (Bignoniaceae). In: $48^{\circ}$ Congresso de química: química na proteção ao meio ambiente. (www.abq. org.br/cbq/2008/trabalhos/7/7-222-2563.htm). Acesso em 09/08/2010

Yoder, L.R.; Mahlberg, P.G. 1976. Reactions of alkaloid and histochemical indicators in laticifers and specialized parenchyma cells of Catharanthus roseus (Apocynaceae). American Journal of Botany, 63: 1167-1173.

Zoghbi, M.G.B. ; Guilhon, G.M.S. ; Pereira, R.A.; Lima, G.S.L. 2007. Nova fonte de sulfetos de dialila: óleo essencial e extrato hexânico de Mansoa standleyi (Bignoniaceae). IV Simpósio Brasileiro de óleos essenciais. Fortaleza,CE. (www.ivsboe.padetec. ufc.br/CDSimposio/.../Resumo_ZoghbiMGB.pdf.). Acesso em 5/05/ 2011

Recebido em: 12/04/2011

Aceito em: 04/10/2011 
